\title{
Model Read, Answer, Discuss, Explain, and Create untuk Meningkatkan Hasil Belajar IPS Siswa Pada Pembelajaran Daring
}

\author{
Chika Chelita Chairunnisa*, Prihantini,Rendi Restiana Sukardi \\ Universitas Pendidikan Indonesia Kampus Cibiru, Bandung, Indonesia \\ *Coresponding Author: chikachelita@upi.edu
}

Article History:

Received 2021-12-17

Revised 2022-01-20

Accepted 2022-02-05

DOI:

10.31949/educatio.v8i1.1819

\begin{abstract}
The background of this research is that there are still many teachers who find it difficult to explain the syntax of existing learning models and the problem of teacher confusion in choosing the right learning model to improve student learning outcomes in online learning. This study aims to describe the application of the RADEC (Read-Answer-Discuss-Explain-Create) model to improve social studies learning outcomes for fourth grade students at SDN Kalimulya 1. This research is a classroom action research (CAR) which was carried out in 2 gycles. Data collection techniques in the form of interviews, documentation, observation and evaluation sheet tests. Data were analyzed descriptively qualitatively and quantitatively. Based on the results of the data analysis of student learning outcomes before using the RADEC Model by 46\%, after the first cycle it increased to 69\% Then in the second cycle it increased again to $91 \%$ so it can be concluded that the RADEC (Read-Answer-Discuss-ExplainCreate) Model can improve social studies learning outcomes for Class IV at SDN Kalimulya 1 and become an alternative model that can be used by teachers in learning. The advantages of this model are that it can be a solution to the problem of students' low interest in reading and increase students activeness and confidence in communicating orally or in writing.

Keywords: RADEC learning model; social studies learning outcomes; online learning
\end{abstract}

\section{PENDAHULUAN}

Pembelajaran adalah suatu kegiatan yang dilakukan oleh pendidik secara sengaja berupa pengorganisasian suatu sistem lingkungan agar terjadi suatu proses belajar dengan berbagai metode untuk peserta didik dapat berinteraksi dengan berbagai komponen didalamnya (Prihantini, 2021). Saat ini, proses pendidikan berdasarkan Permendikbud No. 22 Tahun 2016 mengamanatkan pembelajaran kurikulum 2013 dengan menitikberatkan keaktifan peserta didik. Hal ini dilatar belakangi oleh fakta bahwa pembelajaran yang 
selama ini dilakukan terlalu berorientasi pada aktivitas menyuapi pengetahuan ke peserta didik (Tembang et al., 2017) sehingga daya berpikir kreatif dan kritisnya tidak terasah atau hanya menekankan aspek kognitif sehingga aspek psikomotor dan sikap siswa tidak dapat berkembang seutuhnya. Selain fenomena tersebut, fenomena terkait rendahnya literasi membaca siswa, berdasarkan hasil PISA 2018, menempatkan Indonesia pada peringkat ke-72 dari 78 Negara dalam kategori membaca (OECD 2019). Kedua fenomena tersebut mendorong pentingnya penguasaan kompetensi siswa secara menyeluruh, terlebih saat ini adanya globalisasi membawa segala perubahan dalam berbagai bidang terutama dalam IPTEK yang memunculkan gagasan bahwa sebuah bangsa dan negara dikatakan maju apabila sumber daya manusianya dapat bersaing secara global, oleh karena itu kebutuhan keterampilan abad 21 menjadi urgensi. Keterampilan abad 21 dengan istilah 4C yakni Critical Thinking and Problem Solving, Creativity, Communication and Collaboration (Prayogi et al., 2019) memunculkan sebuah istilah baru dalam dunia pendidikan yakni pembelajaran abad 21 yang menghendaki internalisasi keterampilan 4C, literasi dasar dengan penggunaan dan penguasaan TIK. Menelusuri lebih lanjut terkait hal tersebut, sektor pendidikan dalam merespon tuntutan tersebut berimplikasi pada kebutuhan pembelajaran yang mengintegrasikan keterampilan berpikir tingkat tinggi atau HOTS (High Order Thinking Skill). HOTS merupakan kemampuan berpikir yang membuat siswa harus mengolah sebuah informasi dengan kegiatan menganalisis, mengevaluasi dan menciptakan atau berdaya cipta (Fanani et al., 2014:3) sehingga siswa tidak hanya melihat sebuah permasalahan tetapi juga mampu memecahkan permasalahan dengan sebuah ide, gagasan ataupun karya solutif. Salah satu bidang studi di SD yang mesti memasukkan unsur HOTS adalah Ilmu Pengetahuan Sosial (IPS). IPS adalah mata pelajaran yang memberikan pengetahuan, keterampilan dan penginternalisasian sikap kepada peserta didik melalui materi pembelajaran yang menyorot fenomena sosial di lingkungan terdekat anak (Chairunnisa et al., 2021) sehingga diharapkan peserta didik dapat mengidentifikasi,menganalisis sebuah fenomena sosial di sekitarnya untuk akhirnya secara kreatif dan inovatif memecahkan masalah dengan menciptakan sebuah ide, gagasan ataupun produk. Oleh karena itu, pembelajaran IPS di SD menjadi sebuah bidang studi yang memiliki urgensi untuk dilaksanakan secara efektif.

Pada tahun 2019, dunia pendidikan dihantam oleh wabah penyakit global yang menghendaki adanya transformasi digital yang mana sebuah pembelajaran jarak jauh atau daring menjadi pilihan urgen dalam mengatasi wabah global yaitu COVID-19. Keadaan yang mendadak ini membutuhkan penyesuaian cepat oleh guru. Penyesuaian tersebut memengaruhi bagaimana guru menyusun berbagai komponen-komponen pembelajaran agar tercipta sebuah pembelajaran efektif. Salah satu komponen pembelajaran yang tidak lepas dari kesulitan yang dihadapi guru adalah model pembelajaran. Model pembelajaran yang digunakan guru saat pandemi menjadi tidak jelas bahkan tidak tersiratkan. Pembelajaran yang tercipta menjadi tidak sesuai dengan pembelajaran abad ke 21 dan tidak sesuai dengan amanat kurikulum 2013. Aktivitas siswa ketika pembelajaran daring hanya sebatas pengerjaan soal lalu dikumpulkan, disisi lain ada juga guru yang ingin membuat pembelajaran daring efektif tetapi kebingungan terkait model pembelajaran apa yang baiknya digunakan. Permasalahan serupa juga terjadi di Kelas IV SD Negeri Kalimulya 1 pada pembelajaran IPS, ditemukan bahwa guru masih bingung dalam memilih model pembelajaran yang digunakan karena model pembelajaran yang ada, dianggap memiliki sintaks yang sulit dalam penjabarannya, guru sulit menyusun model pembelajaran inovatif yang sesuai kurikulum 2013 terlebih dalam situasi pembelajaran daring saat ini yang mana guru tidak hanya harus menyesuaikan model pembelajaran tetapi juga memiliki kesulitan dalam penggunaan teknologi. Kesulitan tersebut membuat rendahnya hasil belajar IPS mengenai materi berbagai pekerjaan oleh siswa.

Permasalahan-permasalahan di atas mengindikasi perlunya Solusi berupa Inovasi model pembelajaran yang tidak terlalu sulit di pahami guru sintaksnya, sesuai kebutuhan serta memiliki kemudahan penerapannnya dalam pembelajaran daring sehingga hasil belajar siswa meningkat. Model pembelajaran yang dapat menjadi salah satu solusi tersebut adalah model pembelajaran RADEC (Read-Answer-Discuss-Explain-Create). Model ini sangat bagus untuk pengembangan karakter, keterampilan abad 21, dan literasi (Pratama et al., 2019) karena siswa diajak untuk membaca terlebih dahulu dalam mengeksplor pengetahuan lalu menjawab berdasarkan kemampuan berpikir, dilanjutkan berdiskusi secara berkolaborasi, mempresentasi lalu terakhir menciptakan sesuatu. Selain itu sintaks model RADEC mudah dihafal (Sopandi, 2017). Penelitian sebelumnya 
membuktikan bahwa model RADEC memiliki pengaruh positif terhadap peningkatan kemampuan berpikir siswa dan pemahaman konsep sehingga meningkatkan hasil belajar siswa sekolah dasar (Handayani et al., 2019; Pratama, et al., 2020; Tulljanah et al., 2021; Setiawan et al., 2020; Setiawan et al., 2020; Wahyuni et al., 2020). Penelitian ini mencoba menerapkan model RADEC sebagai solusi rendahnya hasil belajar IPS siswa dalam pembelajaran daring. Berdasarkan uraian latar belakang di atas dan penelitian penelitian terdahulu, perlu sekiranya dilakukan sebuah penelitian lebih lanjut terkait penerapan Model RADEC di mata pelajaran lain dan dalam rangka menjawab kebutuhan model pembelajaran yang mudah di aplikasikan pada pembelajaran daring. Oleh sebab itu penelitian ini bertujuan untuk mendeskripsikan penerapan Model RADEC (Read-Answer-Discuss-Explain-Create) dalam meningkatkan hasil belajar materi IPS siswa kelas IV di SDN Kalimulya 1.

\section{METODE PENELITIAN}

Pelaksanaan penelitian ini menggunakan jenis metode Penelitian Tindakan Kelas (PTK) dengan tujuan untuk memperbaiki praktik pembelajaran (Mulyasa et al., 2012:10) dengan begitu peneliti mengharapkan terciptanya pembelajaran daring yang lebih efektif, berkualitas dan mampu meningkatkan hasil belajar. Prosedur PTK dilakukan melalui empat tahapan yaitu: 1) Perencanaan, 2) pelaksanaan, 3) pengamatan, dan 4) refleksi (Arikunto et al., 2012). Penelitian ini dilakukan secara berkolaboratif oleh peneliti dan guru dalam dua siklus, yang dilaksanakan dari tanggal 1 November 2021-5 November 2021 dengan subjek penelitian yaitu siswa kelas IV C SD Negeri Kalimulya 1, Kota Depok berjumlah 35 orang dengan objek penelitian yakni kemampuan siswa dalam memahami materi pelajaran IPS berbagai pekerjaan pada pembelajaran daring melalui model RADEC. Teknik pengumpulan data berupa wawancara, dokumentasi, observasi dan tes berupa lembar evaluasi sebagai koleksi data mengenai hasil belajar IPS, berjumlah 20 soal dengan tiap soal memiliki skor 5 sehingga skor maksimal 100. lalu dalam teknik analisis data yang digunakan adalah kuantitatif untuk menganalisis hasil tes evaluasi. Indikator keberhasilan hasil belajar menggunakan Kriteria Ketuntasan Minimum yang sudah ditetapkan SD Negeri Kalimulya 1 yaitu minimal 70. Data kuantitatif dihasilkan dari perhitungan rerata dan persentase ketuntasan belajar. Sedangkan, teknik analisis kualitatif digunakan hasil observasi untuk mendeskripsikan berlangsungnya penelitian.

\section{HASIL DAN PEMBAHASAN}

Berdasarkan wawancara dengan guru diketahui bahwa guru tidak menggunakan model pembelajaran yang spesifik dan hanya menggunakan model pembelajaran konvensional saja. Pembelajaran daring dilakukan melalui whatsapp dengan metode berupa penugasan, setiap memasuki ke tema awal dilakukan pertemuan tatap maya melalui zoom meeting. Siswa sendiri dalam pembelajaran tatap maya melalui zoom menurut guru cukup aktif merespon, namun memang dalam pelaksanaan pembelajaran ketika menggunakan metode penugasan, banyak siswa yang selalu mengumpulkan tugas terlambat sampai berhari-hari. Dalam rangka mengetahui pemahaman siswa pada materi pelajaran IPS materi berbagai pekerjaan sebelum dilaksanakan model pembelajaran RADEC, peneliti melakukan prasiklus berupa pretest. Pretest dilakukan dengan mengedepankan kejujuran dan transparansi siswa dengan menggunakan aplikasi quizziz dan setiap siswa dipastikan oncam dalam pengerjaannya melalui zoom meeting. Hasil pretest menunjukkan bahwa hasil belajar belum nampak ketuntasan. Hasil yang didapatkan dari 35 siswa, nilai terendah yaitu 40 dan nilai tertinggi 85 dengan rata-rata nilai adalah 66,85 yakni sebanyak 16 siswa (46\%) yang telah mencapai KKM dan yang belum mencapai KKM sebanyak 19 siswa (54\%).

Penelitian menggunakan model pembelajaran RADEC (read-answer-discuss-explain-create) dilaksanakan 2 siklus. Setiap siklus dilaksanakan 2 pertemuan, dari setiap siklus tersebut diperoleh data hasil belajar. Siklus I diawali dengan perencanaan yaitu membuat RPP, menyiapkan bahan materi, sumber dan media pembelajaran berupa PPT Interaktif dan video, membuat soal pra pembelajaran, membuat lembar observasi. Pelaksanaan tindakan diawali dengan guru menyapa melalui whatsapp group, mengarahkan siswa untuk membaca informasi dari berbagai sumber disini guru dapat menyarankan beberapa sumber. Pembiasaan membaca 
merupakan bentuk belajar mandiri siswa (Sahan, Muin., 2021:38), di sisi lain kegiatan ini juga akan membuat kondisi siswa menjadi siap belajar (Tuba., 2017) di sisi lain dapat meningkatkan kemampuan menggali dan menganalisis informasi (Andini et al., 2021:1436). Langkah selanjutnya adalah siswa menjawab soal pra pembelajaran yang dikirim melalui google form dan mengumpulkan sesuai waktu yang sudah ditentukan. Langkah ini mendorong siswa membangun kemampuan berpikir kritis sebagai lanjutan dari analisa sumber bacaan sebelumnya (Sopandi., 2019) dengan hal ini juga guru dapat mengetahui pemahaman siswa sudah sampai mana (Pohan et al., 2021) kemudian, guru mengarahkan untuk memulai tatap maya melalui zoom, guru menyapa, berdoa, dan melakukan apersepsi, siswa dibentuk kelompok secara heterogen, diarahkan untuk berdiskusi melalui breakout room mengenai jawaban pra pembelajaran yang sudah dijawab secara individu sebelumnya kemudian menyepakati bersama jawaban yang benar, lalu perwakilan kelompok mepresentasikan hasil diskusinya dan siswa dari kelompok lain diberi kesempatan untuk membantah, menambahkan atau bertanya. Pada tahap observasi dilakukan pengamatan terhadap berlangsungnya pembelajaran. Pada tahap refleksi, data hasil observasi dan evaluasi dikumpulkan dan dikaji bersama guru, hasil evaluasi siswa berupa tes diperoleh bahwa hasil belajar siswa belum mencapai ketuntasan maka diadakan tindakan lanjutan pada siklus II. Berdasarkan hasil tes berupa evaluasi dari 35 siswa menggunakan aplikasi quizziz pada siklus I didapatkan nilai terendah yaitu 60 sedangkan nilai tertinggi yaitu 85 dengan rata-rata nilai adalah 70,28 yakni sebanyak 24 siswa (69\%) yang telah mencapai KKM dan yang belum mencapai KKM sebanyak 11 siswa (31\%). Pada siklus I kendala yang dihadapi antara lain 1) hasil nilai rata-rata masih rendah dan belum tuntas 2) masih terdapat siswa yang tidak aktif dalam kelompok 3) ada beberapa siswa yang telat mengumpulkan pra pembelajaran.

Siklus II diawali dengan perencanaan yaitu membuat RPP, menyiapkan bahan materi, sumber dan media pembelajaran berupa PPT Interaktif dan video, membuat soal pra pembelajaran, membuat lembar observasi. Disini guru melakukan koordinasi dengan para orang tua untuk mendampingi anaknya agar dapat mengikuti proses pembelajaran sesuai dengan waktunya. Pelaksanaan tindakan diawali dengan guru menyapa melalui whatsapp group, mengarahkan siswa untuk membaca informasi dari berbagai sumber disini guru dapat menyarankan beberapa sumber, siswa diminta untuk menjawab soal pra pembelajaran yang dikirim berupa google form dan mengingatkan untuk dikumpulkan dengan tepat waktu, guru mengarahkan untuk memulai tatap maya melalui zoom, guru menyapa, berdoa, dan melakukan apersepsi, siswa dibentuk kelompok secara heterogen, diarahkan untuk berdiskusi melalui breakout room mengenai jawaban pra pembelajaran untuk disepakati bersama jawaban yang benar, lalu perwakilan kelompok mepresentasikan hasil diskusinya dan siswa dari kelompok lain diberi kesempatan untuk membantah, menambahkan atau bertanya. Pada tahap observasi dilakukan pengamatan terhadap berlangsungnya pembelajaran. Pada tahap refleksi, data hasil observasi dan evaluasi dikumpulkan dan dikaji bersama guru.

Tabel 1. Perbandingan Hasil Belajar siswa pada Prasiklus, Siklus I dan Siklus II

\begin{tabular}{|c|c|c|c|c|c|c|c|}
\hline \multirow[b]{2}{*}{ Nilai } & \multirow[b]{2}{*}{$\begin{array}{c}\text { Ketuntasan } \\
\text { KKM } 70\end{array}$} & \multicolumn{2}{|c|}{ Prasiklus } & \multicolumn{2}{|c|}{ Siklus I } & \multicolumn{2}{|c|}{ Siklus II } \\
\hline & & $\begin{array}{l}\text { Jumlah } \\
\text { siswa }\end{array}$ & $\%$ & $\begin{array}{l}\text { Jumlah } \\
\text { siswa }\end{array}$ & $\%$ & $\begin{array}{l}\text { Jumlah } \\
\text { siswa }\end{array}$ & $\%$ \\
\hline$>70$ & $\begin{array}{l}\text { Mencapai } \\
\text { KKM }\end{array}$ & 16 & 46 & 24 & 69 & 32 & 91 \\
\hline$<70$ & $\begin{array}{l}\text { Belum } \\
\text { Mencapai } \\
\text { KKM }\end{array}$ & 19 & 54 & 11 & 31 & 3 & 9 \\
\hline \multicolumn{2}{|c|}{ Rata-rata } & \multicolumn{2}{|c|}{66,85} & \multicolumn{2}{|c|}{70,28} & \multicolumn{2}{|c|}{84,42} \\
\hline \multicolumn{2}{|c|}{ Nilai tertinggi } & \multicolumn{2}{|c|}{85} & \multicolumn{2}{|c|}{85} & \multicolumn{2}{|c|}{90} \\
\hline \multicolumn{2}{|c|}{ Nilai terendah } & \multicolumn{2}{|c|}{40} & \multicolumn{2}{|c|}{60} & \multicolumn{2}{|c|}{60} \\
\hline
\end{tabular}

Berdasarkan hasil tes evaluasi menggunakan aplikasi quizziz diperoleh bahwa hasil belajar siswa pada siklus II terjadi peningkatan, dari 35 siswa didapatkan nilai terendah yaitu 60 sedangkan nilai tertinggi yaitu 90 dengan rata-rata nilai adalah 84,42 yakni sebanyak 32 siswa (91\%) yang telah mencapai KKM dan yang belum 
mencapai KKM sebanyak 3 siswa (9\%). Maka dari itu disimpulkan bahwa hasil belajar sudah mencapai ketuntasan oleh karena itu tidak perlu dilakukan siklus berikutnya. Meningkatnya hasil belajar siswa berdasarkan hasil observasi selama pembelajaran yaitu dikarenakan keaktifan dan keantusiasan siswa yang mulai terlihat baik dalam kelompok maupun dengan guru, mulai dapat beradaptasi dengan model pembelajaran RADEC dan siswa yang terlambat mengikuti pembelajaran juga sudah teratasi berkat dukungan orang tua untuk menfasilitasi anaknya dalam mengikuti proses kegiatan belajar mengajar secara daring. Perbandingan Hasil Belajar siswa yang sudah dilaksanakan dari Prasiklus, Siklus I hingga Siklus II dapat dilihat pada tabel 1. Dari hasil tersebut tampak bahwa hasil belajar IPS siswa meningkat. Peningkatan tersebut terlihat dari persentase siswa yang tuntas serta rata-rata nilai yang diperoleh siswa di kelas 4C SD Negeri Kalimulya 1 Kota Depok. Hasil penelitian ini sekaligus mendukung dan memperkuat hasil dan temuan dari penelitian-penelitian yang dilakukan oleh Handayani et al. (2019), Pratama, et al. (2020), Tulljanah et al. (2021), Setiawan et al. (2020), Setiawan et al. (2020), dan Wahyuni et al. (2020), yang menyebutkan bahwa model RADEC efektif dalam meningkatkan kemampuan dan hasil belajar siswa di sekolah dasar.

\section{KESIMPULAN}

Berdasarkan hasil analisis data dan penelitian dapat disimpulkan bahwa Penerapan Model pembelajaran RADEC (read-answer-discuss-explain-create) di Kelas 4C SD Negeri Kalimulya 1 Kota Depok dapat menjadi alternatif guru untuk digunakan dalam pembelajaran IPS karena sintaksnya yang mudah dimengerti dan diaplikasikan oleh guru khususnya dalam pembelajaran daring. Selain itu model ini akan menjadi solusi terhadap permasalahan rendahnya minat membaca siswa, dan meningkatkan keaktifan serta kepercayaan diri siswa dalam berkomunikasi lisan atau tulisan dalam rangka mengekspresikan pendapatnya. Hasil belajar siswa pada prasiklus atau sebelum menggunakan Model RADEC diperoleh sebesar 46\% dengan jumlah siswa sebanyak 16 orang sudah mencapai ketuntasan hasil belajar, dan yang belum mencapai ketuntasan sebesar 54\% dengan jumlah siswa sebanyak 19 orang. Setelah dilaksanakan siklus I ketuntasan hasil belajar meningkat menjadi $69 \%$ dengan jumlah siswa yang telah tuntas sebanyak 24 orang dan yang belum memperoleh ketuntasan sebesar 31\% dengan jumlah siswa sebanyak 11 orang. Kemudian dilaksanakan siklus II dengan peningkatan hasil belajar yang signifikan yakni 91\% siswa telah mencapai ketuntasan yaitu sebanyak 32 orang dan yang belum memperoleh ketuntasan sebesar 9\% dengan jumlah siswa sebanyak 3 orang. Model pembelajaran RADEC (read-answer-discuss-explain-create) yang diterapkan menunjukkan hasil positif terhadap peningkatan hasil belajar siswa dengan kategori sangat tinggi yaitu $91 \%$ pada siklus II. Dapat disimpulkan bahwa penelitian ini mendukung penelitian-penelitian yang sudah ada bahwa model RADEC dapat meningkatkan hasil belajar siswa.

\section{DAFTAR PUSTAKA}

Andini, S. R., \& Fitria, Y. (2021). Pengaruh Model RADEC pada Pembelajaran Tematik Terhadap Hasil Belajar Peserta Didik Sekolah Dasar.Jurnal Basicedu, 5(3), 1435-1443. doi: 10.31004/basicedu.v5i3.960.

Arikunto, S. Suhardjono. \& Supardi. (2012). Penelitian Tindakan Kelas. Jakarta: Bumi Aksara.

Chairunnisa, C. C., Az-Zahra, J. F., Istianti, T., \& Arifin, M. H. Analisis Materi IPS Kelas IV Tema Berbagai Pekerjaan dengan HOTS.

Fanani, A., \& Kusmaharti, D. (2018). Pengembangan pembelajaran berbasis HOTS (higher order thinking skill) di sekolah dasar kelas V. Jurnal Pendidikan Dasar, 9(1), 1-11..

Handayani, H., Sopandi, W., Syaodih, E., Suhendra, I., \& Hermita, N. (2019, November). RADEC: An Alternative Learning of Higher Order Thinking Skills (HOTs) Students of Elementary School on Water Cycle. In Journal of Physics: Conference Series (Vol. 1351, No. 1, p. 012074). IOP Publishing..

Mulyasa. (2012). Praktek Penelitian Tindakan Kelas. Bandung: PT Remaja Rosdakarya. 
OECD. (2019). Programme for international student assessment (PISA) results from PISA 2018. Oecd 1-10.

Pohan, A. A., Abidin, Y., \& Sastromiharjo, A. (2020). Model Pembelajaran Radec Dalam Pembelajaran Membaca Pemahaman Siswa. In Seminar Internasional Riksa Bahasa (pp. 250-258)..

Pratama, Y. A., Sopandi, W., \& Hidayah, Y. (2019). RADEC Learning Model (Read-Answer-Discuss-Explain And Create): The Importance of Building Critical Thinking Skills In Indonesian Context. International Journal for Educational and Vocational Studies, 1(2), 109-115..

Pratama, Y. A., Sopandi, W., Hidayah, Y., \& Trihatusti, M. (2020). Pengaruh model pembelajaran RADEC terhadap keterampilan berpikir tingkat tinggi siswa sekolah dasar. JINoP Jurnal Inovasi Pembelajaran), 6(2), 191-203.

Prayogi, R. D. (2020). Kecakapan Abad 21: Kompetensi Digital Pendidik Masa Depan. Manajemen Pendidikan, 14(2). doi: 10.23917/jmp.v14i2.9486.

Prihantini. (2021). Strategi Pembelajaran SD. Jakarta: Bumi Aksara.

Sahan, P., Muin, A., \& Jauhar, S. (2021). Hubungan antara Kebiasaan Membaca Dengan Hasil Belajar Bahasa Indonesia Siswa di SD Inpres 12/79 Macanang. JPPSD: Jurnal Pendidikan dan Pembelajaran Sekolah Dasar, 1(1), 35-44.

Setiawan, D., Sopandi, W., \& Hartati, T. (2020). The influence of read, answer, disscuss, explain, and create (RADEC) learning model on the concept mastery of elementary school students on the water cycle topic. In Journal of Physics: Conference Series (Vol. 1521, No. 4, p. 042113). IOP Publishing. doi: 10.1088/1742-6596/1521/4/042113.

Sopandi, W. (2017). The quality improvement of learning processes and achievements through the readanswer-discuss-explain-and create learning model implementation. In Proceeding 8th Pedagogy International Seminar (Vol. 8, pp. 132-139).

Sopandi, W. (2019). Sosialisasi dan Workshop Implementasi Model Pembelajaran RADEC Bagi Guru-Guru Pendidikan dasar dan Menengah. PEDAGOGLA: Jurnal Pendidikan,8(1), 19-34. doi: 10.21070/pedagogia.v8i1.1853.

Tembang, Y., Sulton., \& Suharjo. (2017). Melalui Model Pembelajaran Think Pair Share Berbantuan Media Gambar Di Sekolah Dasar. Jurnal Pendidikan: Teori, Penelitian, dan Pengembangan 2, no(1 Jun. 2017):81217. doi: $10.17977 /$ jptpp.v2i6.9402.

Tuba, S. B. (2017). A Study on Reading Habits of Social Studies and History Teachers in Turkey. Educational Research and Reviews, 12(10), 569-582. doi: 10.5897/err2017.3245.

Tulljanah, R., \& Amini, R. (2021). Model Pembelajaran RADEC sebagai Alternatif dalam Meningkatkan Higher Order Thinking Skill pada Pembelajaran IPA di Sekolah Dasar: Systematic Review. Jurnal Basicedu, 5(6), 5508-5519.

Wahyuni, C., Sudin, A., \& Sujana, A. (2020). Nilai Integritas dan Penguasaan Konsep Peserta Didik Melalui Pembelajaran Radec Berbasis Grup Whatsapp Pada Materi Siklus Air. Jurnal Pena Ilmiah, 3(2), 121 130. 